\title{
Nutrition recommendations and their implementation
}

$\mathrm{N}$ utrition recommendations are - and should be - under continuous debate. New findings challenge old concepts. The media have a preference for news, and rightly so. The increasing interest in diet and health issues among lay people merges with a continuously increasing importance for universities and individual scientists to be visible in the media. Thus, there are many reasons for the often contradictory messages on nutrition and health provided to the general public, leaving the impression of frequent rapid and drastic changes in the science base behind the nutrition recommendations, and therefore requests for changes in these recommendations.

In this context it is important to consider the fact that official nutrition recommendations have been quite stable during the almost 40 years that have passed since the first recommendations appeared. The Scandinavian countries issued such recommendations in the late 1960s. At that time, there was already evidence that reduction in fat intake, particularly saturated fat, would help to decrease risk factors for cardiovascular disease. Developments within the field of dietary fibre in the 1970s and 1980s provided a basis for recommendations regarding intake. The 10 energy per cent limit of added sugars was included in the Nordic recommendations from the beginning. There is, in general, very strong agreement between the most recent Nordic recommendations (NNR 2004) and recommendations in other countries and internationally, e.g. as expressed in the WHO TRS 916 report from 2003 and recent recommendations issued by the Institute of Medicine/Food and Nutrition Board in the USA.

An overview of the scientific basis of current nutrition recommendations was given at a recent symposium in Uppsala, reported in this issue, as a basis for examples and discussions on how to implement these recommendations in practice. Food-based simple messages were highlighted as important and found to be similar in the different Nordic countries in many respects. Such messages should be given and marketed to utilize the potential for health improvements, or avoidance of health deterioration, even during emerging science, and adjusted when there is enough evidence to do so. Evidently, every new significant correlation in observational/epidemiological studies cannot, and should not, lead to changes in recommendations.

Health claims in the marketing of food products may be one way of highlighting nutritional benefits of food products and making them visible to consumers. When used properly and responsibly, such claims may also contribute to consumer education. The new EU regulation of nutrition and health claims became effective on 19 January 2007, almost 4 years after the first draft regulation. The regulation is an important step forward both for producers, who will now have a harmonized European market for their products, and for consumers, who will receive well-founded information and increased protection against false claims. The regulation is summarized and commented on in this issue.

The three original articles in this issue cover quite different, but most relevant fields of nutrition: A study on Nutrition support in hospitalized elderly patients, showing the importance of weight increase or maintenance through proper nutrition; Carboxyl acids in the large bowel as affected by prebiotics and probiotics - there are increasing possibilities to stimulate and regulate carboxyl acid formation through both prebiotics and probiotics, with potential benefits for both colonic and systemic health; and Variability in folic acid content in different varieties of lettuce, showing a potential of increasing considerably the intake of this vitamin by the choice of folate-rich varieties of this popular vegetable.

Nils-Georg Asp

Editor-in-Chief

E-mail: asp@snf.ideon.se 